\title{
THE JOIN PYROPE-KNORRINGITE: EXPERIMENTAL CONSTRAINTS FOR A NEW GEOTHERMOBAROMETER FOR COEXISTING GARNET AND SPINEL.
}

\author{
Brey, ${ }^{(1)} G$.; Doroshev, ${ }^{(2)} A$. and Kogarko, ${ }^{(3)} L$. \\ (1) Max-Planck-Institut für Chemie, D-6500 Mainz, F.R.G.; (2) Inst. Geol. USSR Academy of Sciences, Novosibirsk; \\ (3) Vernadsky Inst. USSR Academy of Sciences, Moscow.
}

Pyropic garnets in lherzolites and harzburgites from diamond-bearing pipes contain significant amounts of chromium. Similar garnets also occur as disseminated grains in kimberlites. Such garnets are usually low in calcium and chromium must be present mostly as the $\mathrm{Mg}_{3} \mathrm{Cr}_{2} \mathrm{Si}_{3} \mathrm{O}_{12}$ end member knorringite. Garnets found as inclusions in diamonds are particularly rich in this component, commonly with 30-40 mol \% knorringite (Meyer and Boyd, 1969; Sobolev et al. 1969) and in a few cases with more than 60 mol-\% (Meyer, 1975; Sobolev et al., 1973). Experimental work on the join pyropeknorringite was already undertaken more than three decades ago (Coes, 1955) but, because of experimental problems, there remains serious disagreement about the pressure stability limit of knorringite (Fig. 1).

Ringwood (1977) synthesized pure knorringite and solid solutions between pyrope and knorringite at pressures between 60 and $80 \mathrm{~kb}$ and temperatures of $1400-1500{ }^{\circ} \mathrm{C}$. Irifune et al. (1982) and Irifune and Hariya (1983) synthesized pure knorringite at pressures greater than $105 \mathrm{~kb}$ and described a stability limit with a positive dP/dT slope. Turkin et al. (1983) brought down the position of the knorringite stability field to 80 - $90 \mathrm{~kb}$ and found a negative $\mathrm{dP} / \mathrm{dT}$ slope. The same group investigated the composition of coexisting garnet and spinel in the 4-mineral harzburgite paragenesis Garss+opx SS $^{+S p} s_{\text {So }}^{+F}$ in the system MASCr from 30 to $70 \mathrm{~kb}$ and showed that (i) the knorringite component in garnet increases with increasing pressure and temperature in this paragenesis (negative dP/dT slopes of $\mathrm{Cr}$-isopleths) and (ii) the picrochromite component in spinel increases with pressure and decreases with temperature (positive dP/dT slopes of $\mathrm{Cr}-$ isopleths). Thus pressure and temperature of crystallisation can be defined uniquely from coexisting garnet and spinel. Moreover, estimated pressures and temperatures are potentially very accurate because the $\mathrm{Cr}$-isopleths for garnet and spinel cut at very steep angles.

These prospects for application to geothermobarometry led us to try to clarify the present situation by reversibly determining the compositions of coexisting phases in piston cylinder and belt apparatuses in the pressure range from 27 to $60 \mathrm{~kb}$ and at temperatures from 1200 to $1500{ }^{\circ} \mathrm{C}$.

Equilibrium composition of coexisting phases were determined reversibly by using mixes of minerals with either high or low $\mathrm{Cr} / \mathrm{Al}$ ratios. Phase compositions were determined from $\mathrm{X}$-ray properties and by electron microprobe.

In a first step we determined the solubility limits of knorringite in pyrope garnets and the composition of coexisting orthopyroxene and corundum-escolaite solid solution and derived thermodynamic mixing parameters for all phases. Extrapolation of our experimental results is consistent with Turkin's et al. (1983) stability limit for pure knorringite with a negative dP/dT slope. 
We also determined the composition of coexisting phases for the 4-phase harzburgitic assembly. Compositions

determined for coexisting garnet ss $_{\text {and }}$ spinel $_{s s}$ are presented in Fig. 2 as a function of pressure and temperature. Based on Fig. 2 we have derived $\mathrm{Cr} /(\mathrm{Cr}+\mathrm{Al})$ isopleths and plotted them in a presssure-temperature-diagram (Fig. 3). There is qualitative agreement with the results of Malinovsky et al. (1975), although position and slopes of Cr-isopleths differ. Straightforward application of the isopleths presented in Fig. 3 to garnet inclusions in diamonds yields a narrow range of pressures of origin for most of these diamonds between 52 and $60 \mathrm{~kb}$. This assumes that these garnets were in equilibrium with spinel; the estimated pressures are minimum values if this was not the case.

The presence of $\mathrm{Fe}$ and $\mathrm{Ca}$ will influence the $\mathrm{Cr}$ contents of the phases and appropriate corrections are needed for a more precise application to natural rock samples. Experiments to determine this influence of $\mathrm{Fe}$ and $\mathrm{Ca}$ are in progress.

Irifune, T. and Hariya, Y. (1983). Mineralogical Journal, 11, $269-281$

Irifune, T., Ohtani, E. and Kumazawa, M. (1982). Phys. Earth Planet. Interiors, 27, 263-272

Malinovsky, I.Y., Doroshev, A.M. and Ran, E.N. (1975). Bull. Inst. Geol. Geophysics, Novosibirsk, 110-115

Meyer, H.O.A. (1975). Geochim. Cosmochim. Acta, 39, 929-936 Meyer, H.O.A. and Boyd, F.R. (1969). Carnegie Inst. Wash. Yearbk., 68, 315-324

Ringwood, A.E. (1977). Earth Planet. Sci. Lett., 36, 443-448 Sobolev, N.V., Lavrent'ev, Y., Pospelova, L. and Sobolev, E. (1969). Dokl. Acad. Sci. USSR, 189, p. 162

Sobolev, N.V., Lavrent'ev, Y., Pokhilenko, N.P. and Usova, L. (1973). Contrib. Mineral. Petrol., 40, 39-

Turkin, A.I., Doroshev, A.M. and Malinovsky, I.Y. (1983).

Bull. Inst. Geol. Geophysics, Novosibirsk, 5-24
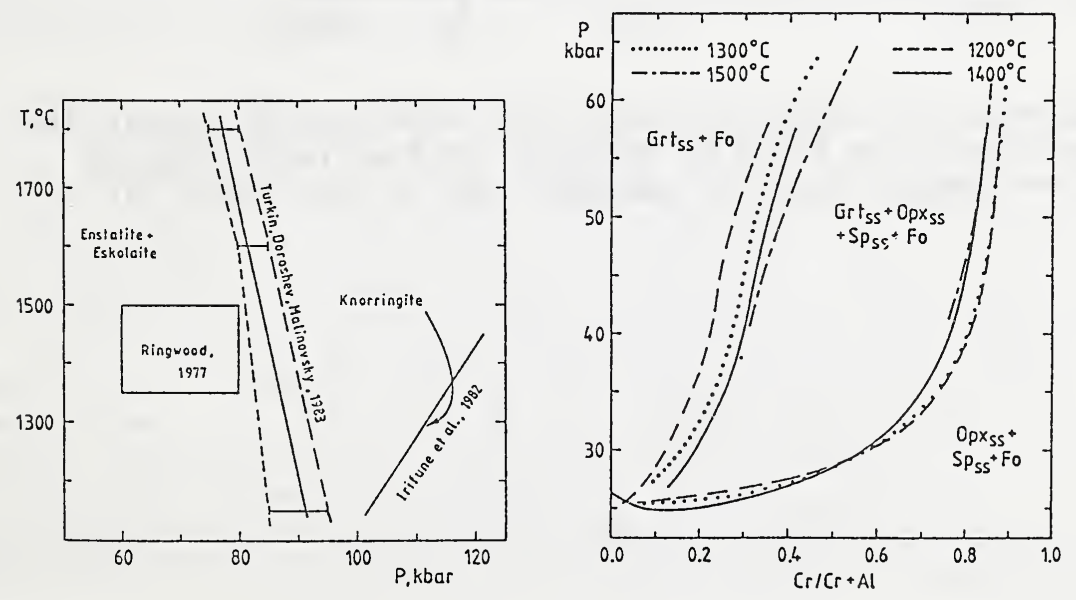

Fig. 1: Pressure stability limits for synthesis of knorringite from enstatite and Eskolaite after various authors

Fig. 2.: Compositions of coexisting garnet and spinel as derived from our experiments 


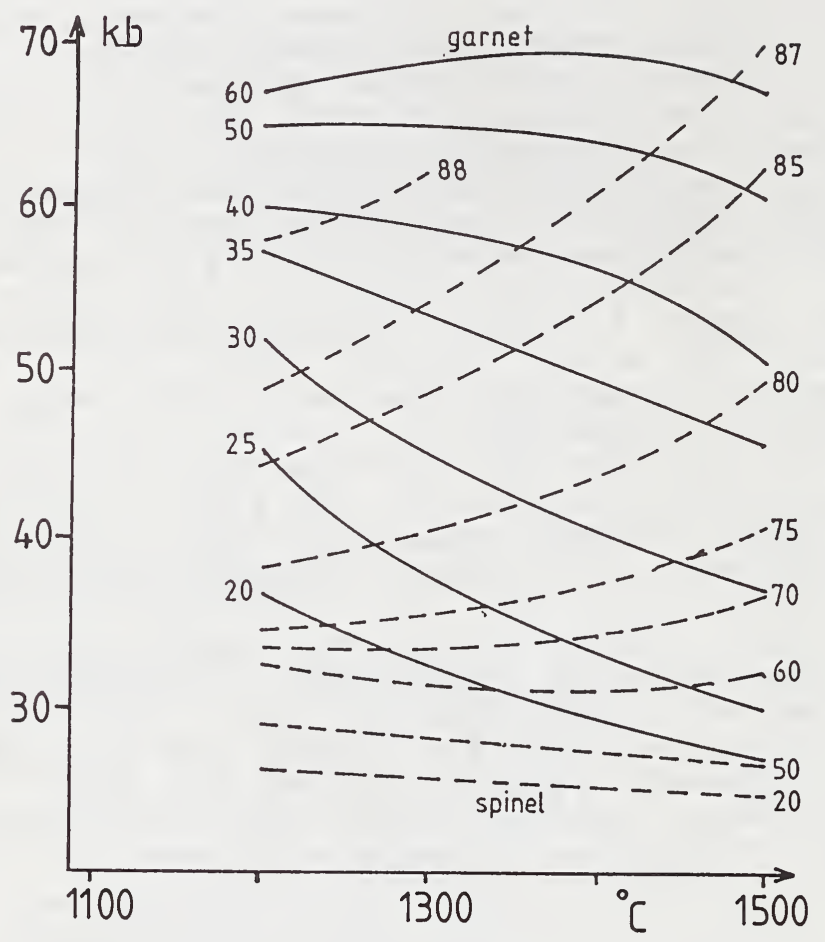

Fig. 3: Isopleths of $100 \times \mathrm{Cr} /(\mathrm{Cr}+\mathrm{Al})$ for coexisting garnet and spinel as derived from Fig. 2. Numbers on the left side of the lines give composition of garnets and on the right of spinels. 